\title{
Artemisinin-based combinations versus amodiaquine plus sulphadoxine-pyrimethamine for the treatment of uncomplicated malaria in Faladje, Mali
}

\author{
Kassoum Kayentao*1, Hamma Maiga1, Robert D Newman², \\ Meredith L McMorrow ${ }^{2}$, Annett Hoppe ${ }^{2}$, Oumar Yattara ${ }^{1}$, Hamidou Traore ${ }^{1}$, \\ Younoussou Kone ${ }^{1}$, Etienne A Guirou ${ }^{1}$, Renion Saye ${ }^{1}$, Boubacar Traore ${ }^{1}$, \\ Abdoulaye Djimde ${ }^{1}$ and Ogobara K Doumbo ${ }^{1}$
}

\begin{abstract}
Address: ${ }^{1}$ Malaria Research and Training Centre, Department of Epidemiology of Parasitologic Diseases, Faculty of Medicine, Pharmacy and Dentistry, University of Bamako, BP 1805, Bamako, Mali and ${ }^{2}$ Malaria Branch, Division of Parasitic Diseases, National Center for Zoonotic, Vectorborne and Enteric Diseases, Centers for Disease Control and Prevention, Atlanta, GA, USA

Email: Kassoum Kayentao* - kayentao@mrtcbko.org; Hamma Maiga - hmaiga@mrtcbko.org; Robert D Newman - ren5@cdc.gov; Meredith L McMorrow - bwe3@cdc.gov; Annett Hoppe - cjn8@cdc.gov; Oumar Yattara - oyattara@mrtcbko.org;

Hamidou Traore - traoreha7906@yahoo.fr; Younoussou Kone - younouskone@mrtcbko.org; Etienne A Guirou - eguirou@mrtcbko.org; Renion Saye - srenion@mrtcbko.org; Boubacar Traore - bouba.traore@mrtcbko.org; Abdoulaye Djimde - adjimde@mrtcbko.org; Ogobara K Doumbo - okd@mrtcbko.org

* Corresponding author
\end{abstract}

Published: 7 January 2009

Malaria Journal 2009, 8:5 doi:10.1186/1475-2875-8-5

This article is available from: http://www.malariajournal.com/content/8/I/5

(c) 2009 Kayentao et al; licensee BioMed Central Ltd.

This is an Open Access article distributed under the terms of the Creative Commons Attribution License (http://creativecommons.org/licenses/by/2.0), which permits unrestricted use, distribution, and reproduction in any medium, provided the original work is properly cited.
Received: 3 October 2008

Accepted: 7 January 2009

\begin{abstract}
Background: Because of the emergence of chloroquine resistance in Mali, artemether-lumefantrine (AL) or artesunateamodiaquine (AS+AQ) are recommended as first-line therapy for uncomplicated malaria, but have not been available in Mali until recently because of high costs.

Methods: From July 2005 to January 2006, a randomized open-label trial of three oral antimalarial combinations, namely $A S+A Q$, artesunate plus sulphadoxine-pyrimethamine (AS+SP), and amodiaquine plus sulphadoxine-pyrimethamine $(A Q+S P)$, was conducted in Faladje, Mali. Parasite genotyping by polymerase chain reaction (PCR) was used to distinguish new from recrudescent Plasmodium falciparum infections.

Results: 397 children 6 to 59 months of age with uncomplicated Plasmodium falciparum malaria were enrolled, and followed for 28 days to assess treatment efficacy. Baseline characteristics were similar in all three treatment groups. The uncorrected rates of adequate clinical and parasitologic response (ACPR) were 55.7\%, 90.8\%, and 97.7\% in AS+AQ, $A S+S P$, and AQ+SP respectively $(P<0.001)$; after PCR correction ACPR rates were similar among treatment groups: $95.4 \%, 96.9 \%$, and $99.2 \%$ respectively $(P=0.17)$. Mean haemoglobin concentration increased across all treatment groups from Day $0(9.82 \pm 1.68 \mathrm{~g} / \mathrm{dL})$ to Day $28(10.78 \pm \mathrm{I} .49 \mathrm{~g} / \mathrm{dL})(\mathrm{p}<0.00 \mathrm{I})$, with the greatest improvement occurring in children treated with AQ+SP. On Day 2, the prevalence of parasitaemia was significantly greater among children treated with AQ+SP (50.8\%) than in children treated with AS+AQ $(10.5 \%)$ or AS+SP $(10.8 \%)$ ( $<<0.00 I)$. No significant difference in gametocyte carriage was found between groups during the follow-up period.
\end{abstract}

Conclusion: The combination of AQ+SP provides a potentially low cost alternative for treatment of uncomplicated $P$. falciparum infection in Mali and appears to have the added value of longer protective effect against new infection. 


\section{Background}

For more than five decades, chloroquine (CQ) has been the main drug for the treatment of uncomplicated malaria in Mali. The emergence of Plasmodium falciparum resistance to CQ has challenged control efforts in Mali, where recent studies indicate that the adequate clinical and parasitological response (ACPR) to CQ is estimated to be less than $50 \%$ in children aged between six months and nine years $[1,2]$ in different endemic settings of the country. These data compelled the Ministry of Health to change to artemisinin-based combination therapy (ACT) for firstline treatment of uncomplicated malaria, in line with the recommendations of the Word Health Organization (WHO) [3]. The two combinations selected were artesunate-amodiaquine (AS+AQ) and artemether-lumefantrine $(\mathrm{AL})$, which were found to be efficacious and well tolerated in the country $[4,5]$.

Unfortunately, the implementation of ACT among the most vulnerable populations living in highly malarious rural areas has been hampered by the limited availability and high cost of the new drugs. In Mali, the healthcare system operates on local cost-recovery, and current prices for ACT in public sector range from 700-1,500 CFA (US\$1.50-4.0). Thus, the majority of patients did not have access to the newly recommended treatment and continued to use chloroquine despite its low efficacy. Therefore, there was a need to test other combination therapies already available in the country before ACT became more widely available. WHO recommendations allow for the use of non-artemisinin combination treatment regimens for the treatment of uncomplicated malaria in settings where the component drugs are efficacious and well tolerated. Data from several settings have demonstrated a similar efficacy between ACT and the combination of amodiaquine plus sulphadoxinepyrimethamine $(\mathrm{AQ}+\mathrm{SP})[6,7]$.

In Mali, SP is still efficacious (in vivo efficacy of 95\%) according to two separate studies $[2,8]$ and is currently authorized only for intermittent preventive treatment during pregnancy (IPTp) [9]. There are data showing good efficacy (adequate clinical and parasitological response (ACPR) of 99.1\%) of AQ in combination with AS [4]. We therefore hypothesized that the combination $A Q+S P$ would be efficacious as suggested by earlier studies in other settings [10-12], and designed a three-arm in vivo efficacy study to evaluate this non-artemisinin containing combination and compare it with two artemisinin-containing combinations (AS+AQ and AS+SP).

\section{Methods}

\section{Study site and population}

The study was conducted in the rural village of Faladje, located $80 \mathrm{~km}$ Northwest of Bamako. The village has a
Catholic mission health center that serves 23,000 inhabitants living in the village and surrounding areas. Malaria transmission is seasonal (July-October) with a peak in October. Most of the population is of the Bambara ethnic group with agriculture as the main occupation.

\section{Study design and procedures}

This was a randomized single-blind trial, conducted between July 2005 and January 2006, that included children between six and 59 months of age living in Faladje. After written informed consent of patients' parents or guardians, study subjects were enrolled if they fulfilled the following WHO in vivo criteria [13]: i) microscope diagnosed mono-infection with $P$. falciparum with a parasitaemia of $2,000-200,000 / \mu \mathrm{l}$, ii) axillary temperature of $\geq$ $37.5^{\circ} \mathrm{C}$, iii) haemoglobin $\geq 5 \mathrm{~g} / \mathrm{dL}$, iv) absence of febrile illness caused by diseases other than malaria, vi) absence of danger signs (inability to stand or drink, convulsions, lethargy or persistent vomiting). Allocation to treatment groups was done according to block randomization (block size of 20); patients were not informed of the drug received.

Treatment was administered according to body weight at the following doses: AQ: $10 \mathrm{mg} / \mathrm{kg} /$ day from day 0 to day 2; AS: $4 \mathrm{mg} / \mathrm{kg} /$ day from day 0 to day 2; SP: $25 \mathrm{mg} / \mathrm{kg}$ of sulphadoxine and $1.25 \mathrm{mg} / \mathrm{kg}$ of pyrimethamine in single dose on day 0 . All drugs were administered directly by the study team and the child was observed for 30 minutes. If vomiting occurred before 30 minutes, the dose was repeated; for vomiting after 30 minutes, a half-dose was administered. In the case of persistent vomiting, the child was referred to a health center for rescue treatment with intramuscular or intravenous quinine and withdrawn from the study.

After the day of enrollment (day 0), the child was assessed on days 1, 2, 7, 14, and 28. Parents/guardians were encouraged to come to the clinic at any time when the child was sick.

\section{Laboratory procedures}

Capillary blood was obtained by fingerpick, thick and thin blood films were prepared and stained with $4 \%$ Giemsa for 20 minutes. Parasite densities were determined from thick blood smears by counting the number of asexual parasites per $300 \mathrm{WBCs}$ assuming a WBC count of $7,500 / \mu \mathrm{l}$. The same estimation method was used to calculate gametocyte density. Slides were read by an experienced medical microscopist, who was blinded to the treatment allocation. A negative blood film was defined as a slide with no parasites after review of 100 fields. Thin blood films were read only for parasite species determination. Ten percent of slides were read by a second reader, 
blinded to initial results. Discordant slides were read by a third microscopist.

Blood haemoglobin concentration was measured using a portable photometer (HemoCue: Anglholm, Sweden) on days $0,14,28$ and any day of failure. Anaemia was defined as haemoglobin $<11.0 \mathrm{~g} / \mathrm{dl}$.

To distinguish recrudescence from new infection, molecular genotyping techniques were used for patients who failed after day 7. At enrollment and during the follow-up visits, blood spots were obtained on filter papers and evaluated at the Molecular Epidemiology and Drug Resistance Unit of the Malaria Research and Training Center in Bamako. Molecular analysis was done according to the following scheme: paired blots (from day 0 and the day of parasitaemia recurrence) were analysed by nested PCR of parasite merozoite surface proteins (MSP1 and MSP2) and microsatellite (CA1), to distinguish between new infection and recrudescence as previously described [5].

\section{Study endpoints classification}

Treatment outcomes were classified following the 2003 WHO antimalarial drug efficacy guidelines [13]. Early Treatment Failure (ETF) was defined as one of the following: a) Danger signs/severe malaria on day 1, 2 or 3 with parasitaemia; b) parasite density on day 2 greater than at day 0 ; c) parasitaemia at day 3 with fever (axillary temperature $\geq 37.5^{\circ} \mathrm{C}$ ); d) parasite density at day 3 equal or greater than $25 \%$ of that at day 0 . Late Clinical Failure (LCF) was defined as danger signs/severe malaria or parasitaemia with fever occurring from day 4 to day 28 without previously meeting the criteria of ETF. Late Parasitological Failure (LPF) was defined as parasitaemia without fever from day 4 to day 28 and without previously meeting any criteria of ETF or LCF. An Adequate Clinical and Parasitological Response (ACPR) was defined as the absence of parasitaemia by day 28 without previously meeting the any criteria for ETF, LCF, or LPF. Outcomes measured were efficacy rates at day 28 with and without PCR adjustment. Other outcomes measured were anemia

Table I: Baseline characteristics of children enrolled in antimalarial in vivo efficacy study, Faladje, Mali.

\begin{tabular}{|c|c|c|c|}
\hline Characteristics & $A S+A Q N=133$ & $A S+S P N=132$ & $A Q+S P N=132$ \\
\hline Mean age \pm S.D. (months) & $34.49 \pm 15.97$ & $36.08 \pm 15.97$ & $37.56 \pm 16.07$ \\
\hline Range & $6-59$ & $6-59$ & $8-59$ \\
\hline Male gender, n (\%) & $72(54.1)$ & $64(48.8)$ & $82(62.1)$ \\
\hline Mean weight \pm SD (kg) & $12.76 \pm 3.30$ & $12.77 \pm 3.42$ & $|3.2| \pm 3.49$ \\
\hline Range & $6.30-23.70$ & $6-19.6$ & $7.70-21.7$ \\
\hline Mean height \pm SD $(\mathrm{cm})$ & $92.05 \pm 12.88$ & $92.86 \pm 14.18$ & $94.39 \pm 14.12$ \\
\hline Range & $63-115$ & $64-120$ & $65-133$ \\
\hline Mean axillary temperature $\pm \mathrm{SD}\left({ }^{\circ} \mathrm{C}\right)$ & $38.59 \pm .77$ & $38.52 \pm .78$ & $38.58 \pm .76$ \\
\hline Range & $37.5-40.2$ & $37.5-40.6$ & $37.5-40.8$ \\
\hline Palpable spleen, n (\%) & $38(28.6)$ & $40(30.3)$ & $49(37.1)$ \\
\hline Mean haemoglobin \pm SD (g/dl) & $9.83 \pm 1.80$ & $9.71 \pm 1.67$ & $9.98 \pm 1.59$ \\
\hline Haemoglobin < II g/dl, n (\%) & $93(69.9)$ & $102(77.3)$ & $97(73.5)$ \\
\hline $\mathrm{GMPD} / \mu \mathrm{l}$ & $24,113.4$ & $22,846.8$ & $24,051.7$ \\
\hline Prior antimalarial use, n (\%) & $\mathrm{II}(8.3)$ & $4(3)$ & $7(5.3)$ \\
\hline Disease duration <= I day, $\mathrm{n}(\%)$ & $83(62.4)$ & $92(69.7)$ & $80(60.6)$ \\
\hline Gametocyte carriage n (\%) & $\mathrm{I}(0.8)$ & $8(6.1)$ & $\mathrm{I}(0.8)$ \\
\hline
\end{tabular}

$\mathrm{AS}+\mathrm{AQ}$, artesunate + amodiaquine; $\mathrm{AS}+\mathrm{SP}$, artesunate + sulphadoxine-pyrimethamine;

$A Q+S P$, amodiaquine + sulphadoxine-pyrimethamine. S.D, Standard deviation:

$\mathrm{G} / \mathrm{dl}$ : Grams per deciliter

GMPD/ $\mu$ l: Geometric Mean Parasite Density per microliter.

P-values (not shown) were calculated from $2 \times 3 X^{2}$ test, (for categorical variables) and by KruskalWallis test (for continuous variables with nonnormal distributions). Groups were not statistically different, except for gametocyte carriage $(p=0.006)$. 
(haemoglobin $<11.0 \mathrm{~g} / \mathrm{dl}$ ) as well as fever, parasite, and gametocyte clearance times.

\section{Ethical approval}

The protocol was approved by the ethical committee of the University of Bamako Faculty of Medicine, Pharmacy, and Odonto-stomatology (FMPOS) and the Institutional Review Board of the United States Centers for Disease Control and Prevention before the study was started. Overall community and local authorities' permission were also obtained in addition to parent or guardian informed consent, according to procedures described earlier [14].

\section{Data entry and analysis}

Data were double entered using Microsoft ACCESS and statistical analysis was performed using SPSS version 11.0 (Chicago, IL, USA). Baseline characteristics of subjects among groups were compared using the chi-square test for categorical variables and Mann-Whitney $U$-test for non-normally distributed continuous variables. The primary analysis was per protocol. Proportion of patients failing treatment was compared across groups using the chi-square test. Paired t test was used to estimate haemoglobin increase from baseline to different time points of regular follow-up. To account for multiple comparisons the results of the tests were considered statistically significant when $\mathrm{p}<0.017$ ( 0.05 divided by 3 ).

\section{Results}

From July 2005 to January 2006, 876 children 6 to 59 months of age were screened for study entry (Figure 1); 397 were enrolled in the study and assigned to treatment arms (Table 1). Baseline characteristics were similar across the three treatment groups except for gametocyte carriage, which was more common among those in the AS+SP group. During follow-up, five children dropped out before day 14 because of travel, and one child whose parasitaemia had resolved died at day 7; the cause of death was unknown (Figure 1). There was no difference between groups regarding the rate of loss to follow-up. At day 28, 391 children were evaluable: 131, 130, and 130 in $\mathrm{AS}+\mathrm{AQ}, \mathrm{AS}+\mathrm{SP}$, and $\mathrm{AQ}+\mathrm{SP}$ treatment arms respectively. Before PCR correction, ACPR was 55.7\%, 90.8\% and $97.7 \%$ in the $\mathrm{AS}+\mathrm{AQ}, \mathrm{AS}+\mathrm{SP}$, and $\mathrm{AQ}+\mathrm{SP}$ arms respectively, and these differences were statistically significant (Table 2). After PCR adjustment, all treatment arms had an ACPR of $>95 \%$, with no statistical difference among the groups (Table 2).

At day 14, the proportion of children with anemia was significantly higher in AS+SP group (77.5\%) when compared with $A Q+S P(61.4 \% ; p=0.0046)$, but not with $\mathrm{AS}+\mathrm{AQ}(65.9 \% ; \mathrm{p}=0.030)$; the difference between the $\mathrm{AS}+\mathrm{AQ}$ and $\mathrm{AQ}+\mathrm{SP}$ groups was not statistically significant (Table 3). Overall, the mean haemoglobin was significantly increased in all treatment groups at day $14(10.17$ $\pm 1.47 \mathrm{~g} / \mathrm{dl})$ when compared with day $0(9.84 \pm 1.68 \mathrm{~g} / \mathrm{dl})$ $(\mathrm{p}<0.01)$ and the greatest increase was observed among

Table 2: Therapeutic efficacy of artesunate + amodiaquine, artesunate + sulphadoxine-pyrimethamine, and amodiaquine + sulphadoxine-pyrimethamine among children with uncomplicated malaria in Faladje, Mali

\begin{tabular}{|c|c|c|c|}
\hline Characteristics & $A S+A Q(N=|3|)$ & $A S+S P(N=130)$ & $A Q+S P(N=130)$ \\
\hline \multicolumn{4}{|c|}{ PCR uncorrected responses on day $28: n$ (\%) } \\
\hline Failures & $58(44.3)$ & $12(9.2)$ & $3(2.3)$ \\
\hline ETF & $0(0)$ & $2(1.5)$ & $0(0)$ \\
\hline LCF & $14(10.7)$ & $2(1.5)$ & $\mathrm{I}(0.8)$ \\
\hline LPF & $44(33.6)$ & $8(6.2)$ & $2(1.5)$ \\
\hline *ACPR & $73(55.7)$ & $118(90.8)$ & $127(97.7)$ \\
\hline \multicolumn{4}{|c|}{ PCR corrected responses on day $28: \mathrm{n} ; \%$} \\
\hline Failures & $6(4.6)$ & $4(3.1)$ & $\mathrm{I}(0.8)$ \\
\hline ETF & $0(0)$ & $2(1.6)$ & $0(0)$ \\
\hline LCF & $2(1.5)$ & $\mathrm{I}(0.8)$ & $0(0)$ \\
\hline LPF & $4(3.1)$ & $\mathrm{I}(0.8)$ & $\mathrm{I}(0.8)$ \\
\hline$* * A C P R$ & $124(95.4)$ & $125(96.9)$ & $129(99.2)$ \\
\hline
\end{tabular}

$\mathrm{AS}+\mathrm{AQ}$, artesunate + amodiaquine; $\mathrm{AS}+\mathrm{SP}$, artesunate + sulphadoxine-pyrimethamine;

$\mathrm{AQ}+\mathrm{SP}$, amodiaquine + sulphadoxine-pyrimethamine

ETF, early treatment failure; LCF, late clinical failure; LPF, late parasitological failure; ACPR, adequate clinical and parasitological response.

Failures are the combination of ETF, LCF, and LPF. Percentages are rounded to achieve $100 \%$ of totals.

$* X^{2}$ test: $p<0.001, A S+A Q$ vs. $A S+S P ; p<0.001, A S+A Q$ vs. $A Q+S P ; p=0.016, A S+S P$ vs. AQ+SP

$* * X^{2}$ test: $p=0.17$ for the comparison of the three treatment arms. 
children treated with $A Q+S P(0.45 \mathrm{~g} / \mathrm{dl})$ followed by AS+AQ $(0.34 \mathrm{~g} / \mathrm{dl})$ and AS+SP $(0.18 \mathrm{~g} / \mathrm{dl})$ (Table 3).

At day 28, the proportion of patients with anemia was $54.3 \%, 59.8 \%$, and $46.2 \%$ in the AS+AQ, AS+SP, and $\mathrm{AQ}+\mathrm{SP}$ groups respectively, but these differences were not statistically significant. Overall, the mean hemoglobin was significantly increased in all treatment groups at day $28(10.78 \pm 1.48 \mathrm{~g} / \mathrm{dl})$ when compared with day $0(9.84 \pm$ $1.68 \mathrm{~g} / \mathrm{dl})(\mathrm{p}<0.001)$; and the most significant increase was observed among children in AQ+SP $(1.07 \mathrm{~g} / \mathrm{dl})$ group followed by AS+AQ $(0.95 \mathrm{~g} / \mathrm{dl})$ and by AS+SP $(0.79 \mathrm{~g} / \mathrm{dl})$ groups.

The proportion of patients with fever decreased from Day $0(100 \%)$ to Day $1(5.8 \%)$, Day $2(2 \%)$, and Day $3(1.5 \%)$ across all treatment arms. No difference was found among treatment groups at scheduled follow-up points with regard to the proportion of patients with fever. There were sharp declines in the proportion of children with parasitaemia from day 0 to day 2 in the AS+AQ $(10.5 \%)$ and AS+SP (10.7\%) groups, but not in AQ+SP $(50.7 \%)$, ( $\mathrm{p}<$ 0.001 ). By day $3,1.5 \%, 0.8 \%$, and $6 \%$ of patients were still parasitaemic in the AS+AQ, AS+SP, and AQ+SP groups respectively $(\mathrm{p}=0.018)$ (Table 3$)$.

From day 0 to day 3 , there was an increase of the proportion of gametocyte carriage followed by a decrease from day 3 to day 28 where that proportion approached zero. No statistical difference in gametocyte carriage between study arms was found at day $3(\mathrm{p}=0.03)$ or day $28(\mathrm{p}=$ 0.16) (Figure 2).

\section{Discussion}

This study illustrated that the non-artemisinin containing combination $\mathrm{AQ}+\mathrm{SP}$ was as efficacious as the artemisinin-

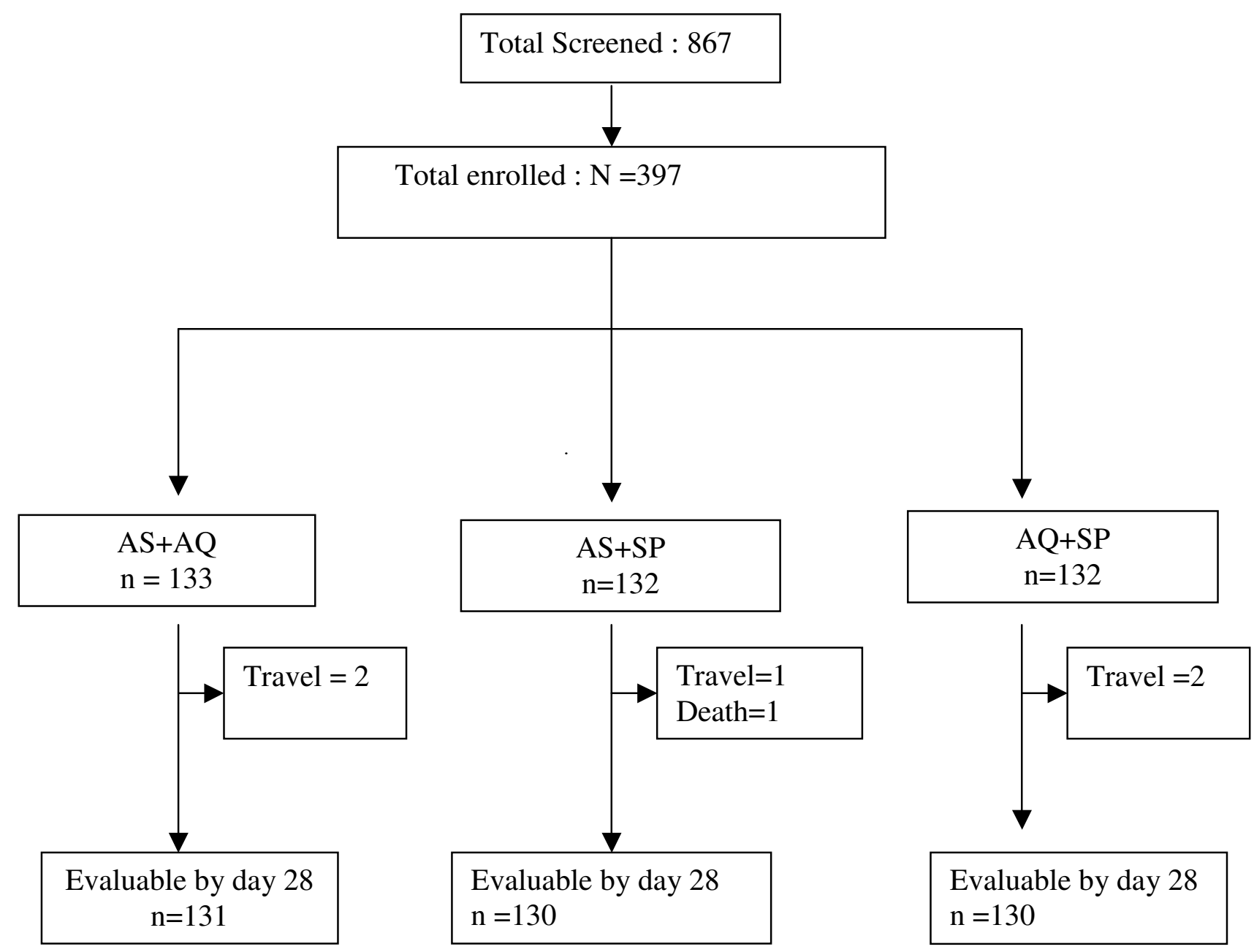

Figure I

Profile of children screened, enrolled, and completing study protocol. 
Table 3: Haemoglobin concentration, anaemia, and parasitaemia among participants in an antimalarial in vivo efficacy study, Faladje, Mali.

\begin{tabular}{|c|c|c|c|}
\hline Characteristics & AS+AQ & AS+SP & AQ+SP \\
\hline \multicolumn{4}{|l|}{ Day 0} \\
\hline $\mathrm{N}$ & 133 & 132 & 132 \\
\hline Mean Haemoglobin \pm S.D $(\mathrm{g} / \mathrm{dl})$ & $9.83 \pm 1.8$ & $9.71 \pm 1.59$ & $9.98 \pm 1.59$ \\
\hline Anaemia $(<\| \mathrm{g} / \mathrm{dl}), \mathrm{n}(\%)$ & $93(69.9)$ & $102(77.3)$ & $97(73.5)$ \\
\hline \multicolumn{4}{|l|}{ Day I4 } \\
\hline $\mathrm{N}$ & $|3|$ & 130 & 130 \\
\hline \$Mean Haemoglobin \pm S.D $(g / d l)$ & $10.17 \pm 1.5$ & $9.89 \pm 1.40$ & $10.43 \pm 1.49$ \\
\hline *Anaemia $(<\mathrm{II} \mathrm{g} / \mathrm{dl}), \mathrm{n}(\%)$ & $87(65.9)$ & $100(77.5)$ & $81(61.4)$ \\
\hline \multicolumn{4}{|l|}{ Day 28} \\
\hline $\mathrm{N}$ & 105 & 127 & 130 \\
\hline$\S S$ Mean Haemoglobin \pm S.D $(g / d l)$ & $10.78 \pm 1.49$ & $10.5 \pm 1.40$ & $11.05 \pm 1.52$ \\
\hline${ }^{* *}$ Anaemia $(<\mathrm{Il} \mathrm{g} / \mathrm{dl}), \mathrm{n}(\%)$ & $57(54.3)$ & $76(59.8)$ & $60(46.2)$ \\
\hline \multicolumn{4}{|l|}{ Parasitaemia, n (\%) } \\
\hline$€$ Day2 & $14(10.5)$ & $14(10.7)$ & $67(50.7)$ \\
\hline$€$ Day3 & $2(1.5)$ & $\mathrm{I}(0.8)$ & $8(6.0)$ \\
\hline Dayl4 & $5(3.8)$ & $2(1.6)$ & $2(1.5)$ \\
\hline$€$ Day28 & $31(29.5)$ & $9(7.1)$ & $3(2.3)$ \\
\hline
\end{tabular}

$\mathrm{AS}+\mathrm{AQ}$, artesunate + amodiaquine; $\mathrm{AS}+\mathrm{SP}$, artesunate + sulphadoxine-pyrimethamine; $\mathrm{AQ}+\mathrm{SP}$, amodiaquine + sulphadoxine-pyrimethamine $* X{ }^{2}$ test: $p=0.014$ overall $(2 \times 3) ; p=0.030, A S+S P$ vs. AS+AQ; $p=0.0046, A S+S P$ vs. $A Q+S P ; p=0.48, A S+A Q$ vs. $A Q+S P$.

$* * X^{2}$ test: $p=0.08$ overall $(2 \times 3) ; p=0.027, A Q+S P$ vs. AS+SP; $p=0.21, A Q+S P$ vs. AS+AQ; $P=0.39, A S+A Q$ vs. AS+SP

\$Paired t-test comparison day 0 vs. day I4: overall, $P<0.01 ; A Q+S P, p=0.00 I ; A S+A Q, p=0.01 \mathrm{I} ; A S+S P, p=0.033$.

\$SPaired t-test comparison day 0 vs. day 28: overall, $p<0.001 ; A Q+S P, p<0.001 ; A S+A Q, p<0.001 ; A S+S P, p<0.00$ I

$€ X^{2}$ test: overall $(2 \times 3)$; Time points showing difference among the three groups: Day $2, p<0.00 \mathrm{I} ;$ Day3, $\mathrm{p}=0.0 \mathrm{I} 7 ; \mathrm{Day} 28, \mathrm{p}<0.00 \mathrm{I}$.

based combinations AS+AQ and AS+SP for the treatment of uncomplicated $P$. falciparum malaria in children aged 6 to 59 months in Faladje, Mali. AQ+SP showed the highest ACPR at day 28 without PCR correction. After PCR correction, AQ+SP demonstrated the highest ACPR, although the difference was not statistically significant. These data corroborate those from other countries, which show the equal or superior efficacy of $\mathrm{AQ}+\mathrm{SP}$ when compared with $A S+A Q[15,16]$ or AS+SP [17]. These data suggest that $\mathrm{AQ}+\mathrm{SP}$ provided greater protection against new infections during the 28-day follow-up period than either AS+AQ or AS+SP. The prevention of new infection provided by $\mathrm{AQ}+\mathrm{SP}$ is probably due to the long elimination half-lives of the component drugs; while in $\mathrm{AS}+\mathrm{AQ}$, the arteminisin is quickly eliminated, providing no post-treatment prophylaxis [18].

Children treated with AQ+SP had a lower prevalence of anaemia on days 14 and 28 than children treated with $\mathrm{AS}+\mathrm{AQ}$ or $\mathrm{AS}+\mathrm{SP}$. Anaemia prevalence appeared to track with parasitaemia prevalence, suggesting that the combination of two longer half-life drugs in $\mathrm{AQ}+\mathrm{SP}$ may provide longer protection against new infections and subsequent anemia. While mean haemoglobin concentration on day 28 was higher among children treated with $A Q+S P$, this difference was not statistically significant. This is in consistent with prior studies, which have demonstrated simi- lar mean haemoglobin concentration between AS+AQ and AQ+SP $[16,17]$.

The two artemisinin-based combinations, AS+AQ and $\mathrm{AS}+\mathrm{SP}$, showed faster parasite clearance than $\mathrm{AQ}+\mathrm{SP}$, but all three regimens resulted in prompt fever reduction. Despite the lower proportion of fever and parasitaemia observed during the first three days after treatment in the two ACT groups, there were more new infections in these groups than in the non-ACT group $(\mathrm{AQ}+\mathrm{SP})$. A greater risk of new infection following treatment with AS+AQ when compared with the AQ+SP has been reported earlier in low [12] and high transmission areas [11,19]. In Mali, $A S+A Q$, co-blistered but not co-formulated, has been introduced nationally as first-line therapy for uncomplicated malaria. However, there are concerns about patient compliance with the large number of tablets, and there is anecdotal evidence that patients may be taking the artesunate pills as monotherapy. With support from the Global Fund, the Malian Ministry of Health is providing AS+AQ free to children less than five years of age. Widespread implementation of ACTs in this vulnerable population should produce a significant reduction in malaria mortality and morbidity in Mali. However, it is essential to continue monitoring the efficacy of this regimen, and to consider alternatives should evidence of resistance develop. 


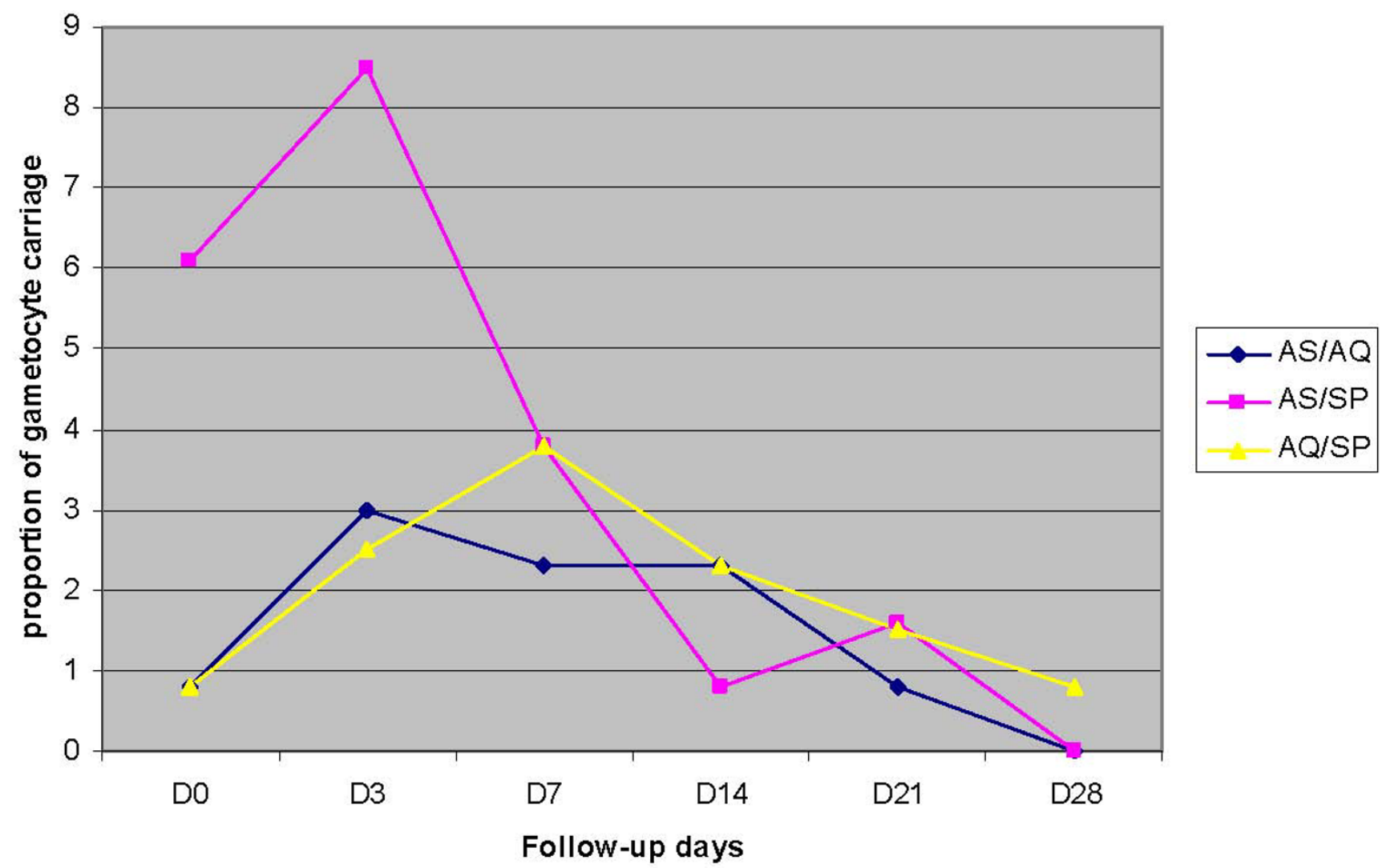

Figure 2

Proportion of children with gametocytes from day 0 to day 28, in Faladje among children aged 6-59 months.

\section{Conclusion}

The combination of $\mathrm{AQ}+\mathrm{SP}$ provides a potentially lowcost alternative for treatment of uncomplicated $P$. falciparum infection in Mali, and appears to have the added value of longer protective effect against new infections.

\section{Competing interests}

The authors declare that they have no competing interests.

\section{Authors' contributions}

In Mali, KK was the principal investigator and HM was the co-principal investigator of the study. At CDC, RN, MM, and $\mathrm{AH}$ contributed to the study design, protocol development, and manuscript writing. OY, HT, YK, EG, and RS participated in data collection, clinical investigation, and laboratory work. BT, AD were involved as field supervisors and laboratory data analysis. OD provided overall supervision in Mali. All authors participated in the writing and review of the final manuscript.

\section{Acknowledgements}

The authors wish to thank the study guides who assisted with assuring participant follow-up. We also extend thanks to the staff of the health center and the community leaders in the village for their support, as well as to the participating children and their families.
This work was supported by the U.S. Centers for Disease Control and Prevention, and by the Malaria and Research Training Center and the University of Bamako on behalf of the Government of Mali.

\section{References}

I. Sangho H, Diawara A, Diallo M, Sow S, Sango HA, Sacko M, Doumbo $\mathrm{O}$ : Assessment of chloroquine resistance two years after stopping chemoprophylaxis in $\mathbf{0}$ to 9 -year-old children living in a malaria-endemic village of Mali. Med Trop 2004, 64(5):506-5I0.

2. De Radigues $X$, Diallo KI, Diallo M, Ngwakum PA, Maiga $H$, Djimde A, Sacko M, Doumbo O, Guthmann JP: Efficacy of chloroquine and sulfadoxine-pyrimethamine for the treatment of uncomplicated falciparum malaria in Koumantou, Mali. Trans R Soc Trop Med Hyg 2006, 100:1013-1018.

3. World Health Organization and UNICEF: World Malaria report 2005. In WHO/HTM/MAL/2005.I/ 02 WHO, Geneva, Switzerland; 2005.

4. Djimdé AA, Fofana B, Sagara I, Sidibe B, Toure S, Dembele D, Dama $S$, Ouologuem D, Dicko A, Doumbo OK: Efficacy, safety, and selection of molecular markers of drug resistance by two ACTs in Mali. Am J Trop Med Hyg 2008, 78:455-46I.

5. Sagara I, Dicko A, Djimde A, Guindo O, Kone M, Tolo Y, Thera MA, Sogoba M, Fofana M, Ouattara A, Sissoko M, Jansen HF, Doumbo OK: $A$ randomized trial of Artesunate-sulfamethoxypyrazine pyrimethamine versus artemether lumefantrine for the treatment of uncomplicated Plasmodium falciparum malaria in Mali. Am J Trop Med Hyg 2006, 75:630-636.

6. Obonyo CO, Juma EA, Ogutu BR, Vulule JM, Lau J: Amodiaquine combined with sulphadoxine/pyrimethamine versus artemisinin-based combinations for the treatment of uncompli- 
cated falciparum malaria in Africa: a meta-analysis. Trans $R$ Soc Trop Med Hyg 2007, I OI: I 17-I 26.

7. Bell BJ, Nyirongo SK, Mukaka M, Zijlstra EE, Plowe CV, Molyneux ME, Ward SA, Winstanley PA: Sulfadoxine-pyrimethamine-Based combinations for malaria: a randomised blinded trial to compare efficacy, safety and selection of resistance in Malawi. Plos ONE 2008, 3:el578.

8. Thera MA, Sehdev PS, Coulibaly D, Traore K, Garba MN, Cissoko Y, Kone A, Guindo A, Dicko A, Beavogui AH, Djimde AA, Lyke KE, Diallo DA, Doumbo OK, Plowe CV: Impact of trimethoprim-sulfamethoxazole prophylaxis on falciparum malaria infection and disease. J Infect Dis 2005, 192: | 823-|829.

9. Kayentao K, Mungai M, Parise M, Kodio M, Keita AS, Coulibaly D, Maiga B, Traoré B, Doumbo OK: Assessing malaria burden during pregnancy in Mali. Acta Trop 2007, 102:106-II2.

10. Faye B, NDiaye JL, NDiaye D, Dieng Y, Faye O, Guaye O: Efficacy and tolerability of four antimalarial combinations in the treatment of uncomplicated Plasmodium falciparum malaria in Senegal. Malar J 2007, 6:80.

II. Mockenhaupt FP, Ehrhardt S, Dzisi SY, Teun Bousema J, Wassilew N, Schreiber J, Anemana SD, Cramer JP, Otchwemah RN, Sauerwein RW, Eggelte TA, Bienzle U: A randomized, placebo-controlled, double-blind trial on sulphadoxine-pyrimethamine alone or combined with artesunate or amodiaquine in uncomplicated malaria. Trop Med Int Health 2005, 10:5 I 2-520.

12. Menard D, Andrianina NNH, Ramiandrasoa Z, Randriamanantena A, Rasoarilalao N, Jahevitra M, Ratsimbasoa A, Tuseo L, Raveloson A: Randomized clinical trial of artemisinin versus non-artemisinin combination therapy for uncomplicated falciparum malaria in Madagascar. Malar J 2007, 6:65.

13. World Health Organization: Assessment and monitoring of antimalarial drug efficacy for the treatment of uncomplicated malaria Geneva: WHO; 2003.

14. Diallo DA, Doumbo OK, Plowe CV, Wellems TE, Emanuel EJ, Hurst SA: Community permission for medical research in developing countries. Clin Infect Dis 2005, 41:255-259.

15. Bakyaita N, Dorsey G, Yeka A, Banek K, Staedke SG, Kamya MR, Talisuna $F$, Kironde F, Nsobya S, Kilian A, Reingold A, Rosenthal PJ, Wabwire-Mangen F: Sulfadoxine-pyrimethamine plus chloroquine or amodiaquine for uncomplicated falciparum malaria: a randomized, multisite trial to guide national policy in Uganda. Am J Trop Med Hyg 2005, 72:573-580.

16. Staedke SG, Mpimbaza A, Kamya MR, Nzarubara BK, Dorsey G, Rosenthal PJ: Combination treatment for uncomplicated falciparum malaria in Kampala, Uganda: randomized clinical trial. Lancet 2004, 364:1950-1957.

17. Rwagacondo CE, Niyitegeka F, Sarushi J, Karema C, Mugsha V, Dujardin JC, Van Overmeir C, Ende J Van Den, d'Alessandr U: Efficacy of amodiaquine alone and combined with sulphadoxinepyrimethamine and of sulphadoxine-pyrimethamine combined with artesunate. Am J Trop Med Hyg 2003, 68:743-747.

18. Krishna S, White NJ: Pharmacokinetics of quinine, chloroquine and amodiaquine. Clinical implications. Clin Pharmacokinet 1996, 30:263-299.

19. Yeka A, Banek K, Bakyaita N, Staedke SG, Kamya MR, Talisuna A, Kironde F, Nsobya SL, Kilian A, Slater M, Reingold A, Rosenthal PJ, Wabwire-Mangen F, Dorsey G: Artemisinin versus monoartemisinin combination therapy for uncomplicated malaria: randomized clinical trials from four sites in Uganda. Plos Med 2005, 2:e 190.
Publish with Biomed Central and every scientist can read your work free of charge

"BioMed Central will be the most significant development for disseminating the results of biomedical research in our lifetime. "

Sir Paul Nurse, Cancer Research UK

Your research papers will be:

- available free of charge to the entire biomedical community

- peer reviewed and published immediately upon acceptance

- cited in PubMed and archived on PubMed Central

- yours - you keep the copyright

Submit your manuscript here:

http://www.biomedcentral.com/info/publishing_adv.asp
BioMedcentral 